\title{
LA FILOSOFÍA DE LA PRAXIS. DOS CONCEPCIONES: ANTONIO GRAMSCI Y ADOLFO SÁNCHEZ VÁZQUEZ ${ }^{1}$
}

\author{
Gabriel Vargas Lozano ${ }^{2}$
}

\begin{abstract}
Resumen:
En este ensayo, se lleva a cabo una confrontación de dos importantes filósofos y luchadores anti-fascistas que comparten la tesis de que la filosofía de Marx es una "filosofía de la praxis", sin embargo, su reflexión discurre por dos vías: en el caso de Sánchez Vázquez precisando el concepto de praxis y planteando diversas formas de ella como praxis creadora en el arte y la sociedad; problemas de la relación entre ética y política, racionalidad y violencia y en el caso de Gramsci desarrollando su teoría de los intelectuales, el bloque histórico, la hegemonía, nueva concepción de la filosofía, guerra de posiciones, guerra de movimiento, catarsis y otras categorías. Se concluye con la necesidad de dar lugar a una nueva concepción unificadora de la filosofía de la praxis.
\end{abstract}

Palabras clave: Filosofía.Filosofía de la praxis.Formas de la praxis.Hegemonía.Intelectuales.Bloque histórico.

\section{THE PHILOSOPHY OF PRAXIS: ADOLFO SÁNCHEZ VÁZQUEZ AND ANTONIO GRAMSCI, TWO CONCEPTIONS}

\begin{abstract}
:
In this essay, two important philosophers and anti-fascist fighters who share the thesis that the Marx's philosophy is a "philosophy of praxis" are confronted.In the text, it is argued that despite their common base, their reflection rather runs in two ways: in the case of Sánchez Vázquez, specifying the concept of praxis and posing various forms of it as creative praxis in art and society; problems of the relationship between ethics and politics, rationality and violence, and in the case of Gramsci, developing his theory of the intellectuals, the historical block, the hegemony, new conception of the philosophy, war of positions, war of movement, catharsis and others categories. The essay concludes by arguing the need to give rise to a unifying new conception of the philosophy of praxis.
\end{abstract}

Key words: Philosophy.Philosophyof praxis.Formsof praxis.Hegemony.Intellectuals.Warof positions.

${ }^{1}$ El presente texto fue presentado, en forma original, en el coloquio internacional "Adolfo Sánchez Vázquez. A cien años de su nacimiento" celebrado en el Aula Magna de la Facultad de Filosofía y Letras de la UNAM, del 1 al 3 de septiembre de 2015.

${ }^{2}$ Filósofo. Profesor-investigador del Departamento de Filosofía de la Universidad Autónoma Metropolitana-Unidad Iztapalapa, Ciudad de México. Ha sido Presidente de la Asociación Filosófica de México; Director de la revista dialéctica publicada desde 1976 por la Universidad Autónoma de Puebla. Actualmente es miembro del comité directivo de la Federación Internacional de Sociedades de Filosofía (FISP) y Presidente de la comisión sobre la enseñanza de la filosofía. Algunos de sus libros son: Intervenciones filosóficas. ¿Qué hacer con la filosofía en América Latina? Ed. UAEM, México, 2007; Filosofía ¿Para qué? Desafíos de la filosofía en el Siglo XXI. Ed. UAM-I, México, 2014; Marx y Freud. Hacia una nueva racionalidad de la sociedad y de la historia (con Raúl Páramo Ortega) Ed. Tirant lo Blanch y UAM-I, México, 2016.E-mail: gvl@xanum.uam.mx 
Como es conocido, el significado de la filosofía para Marx ha sido objeto de múltiples controversias. Las causas de dichas controversias han ampliamente abordadas: la primera y principal fue que el autor de El Capital, no dejó ningún texto en donde dijera qué significaba para él la filosofía, después de la revolución teórica que había hecho con Federico Engels, al establecer las bases del materialismo histórico. En lo que se coincidió fue entonces que había que extraer dicha concepción filosófica de toda su obra pero en especial de los escritos de juventud como la Crítica a la filosofía del Estado de Hegel; los artículos de los Anales franco-alemanes; los Manuscritos económico-filosóficos de 1844; las Tesis sobre Feuerbach y desde luego en losGrudrisse y El Capital ${ }^{3}$. Por cierto, en la Tesis sobre Feuerbach tenemos una síntesis de temas epistemológicos, sociales y filosóficos que requieren una amplia explicación y que culminan con la célebre tesis XI: "los filósofos sólo han interpretado al mundo de distintas maneras; de lo que se trata es de transformarlo" "con la cual se precisaba la diferencia de su concepción con respecto de la tradición filosófica clásica. En efecto, antes de Marx, toda una serie de filósofos desde Platón y Aristóteles hasta la fecha pasando por Kant y Hegel, buscan soluciones para una sociedad que no les satisface, sin embargo, solo proponen un "deber ser", sin embargo, el problema, de acuerdo con Marx es cómo podemos transitar del ser al deber ser. Para ello, Marx inaugura una nueva forma de reflexión transdisciplinaria y fundada en la praxis completamente diferente a las formas tradicionales del pensar filosófico. Considero que este es el problema de fondo.

Ahora bien, en torno a la polémica suscitada en lo que se ha denominado el marxismo desde el siglo XIX hasta la fecha, podemos registrar, por lo menos, doce interpretaciones sobre el significado de la filosofía en Marx: 1) la engelsiana que consideraba que la última filosofía sintetizadora del conocimiento era la de Hegel pero que dado el desarrollo de la ciencia, tendría que ser sustituida por una síntesis producto de todas las disciplinas; 2) la materialista-dialéctica que concebía a la filosofía como ciencia de las ciencias; 3) la ontológica de GeorgyLúkacs, que entendía a la filosofía marxista como un sistema desde el punto de vista del proletariado; 4) la humanista que ponía el acento en el individuo y la liberación de la enajenación (Schaff/Fromm); 5) la

${ }^{3}$ Que en la actualidad se está publicando por el Estado Alemán en 114 volúmenes y 22 tomos que se ha denominado Marx-Engels Gesamtausgabe 2 (AcademieVerlag, Berlín, 2000), para distinguirla de la MEGA1 que fue iniciada por Ryazanov en la URSS.

${ }^{4}$ K. Marx, Tesis sobre Feuerbach, traducción de Bolívar Echeverría incluida en su libro El materialismo de Marx, discurso crítico y revolución. Ed. Itaca, México, 2011. P. 121.

\begin{tabular}{|l|l|l|l|l|}
\hline Q Rovista Dialectus & Ano 5 & n.13 & Agosto - Dezembro 2018 & p. 116-131 \\
\hline
\end{tabular}


cientificista que consideraba a la filosofía como teoría de la práctica teórica o destacamento de la lucha de clases en el seno de la teoría (Althusser); 6) la fenomenológica como la expone Karel Kosik en su Dialéctica de lo concreto; 7) la teoría crítica (Marcuse, Adorno, Horkheimer, primer Habermas o el "discurso crítico" para Bolívar Echeverría); 8) la existencialista que consideraba a la teoría de Marx como una nueva concepción del mundo (Sartre); 9) la metafilosófica (Henri Lefebvre); 10) la posmetafísica(Francisco José Martínez); 11) la posfilosófica (EttieneBalibar) y 12) la filosofia de la praxis. Sin embargo, este concepto ha recibido, a su vez, diversos significados por autores como: Antonio Gramsci, M. Markovic, Wolfgang Fritz Haug, Bertold Brecht, Ernest Bloch, IztvánMézáros, G. Petrovic y Adolfo Sánchez Vázquez. Pero aún queda el austromarxismo con Max Adler y Otto Bauer ${ }^{5}$ quienes pretendieron en forma equivocada "complementar la concepción materialista de la historia con la filosofía kantiana". Hasta aquí, no creo que haya agotado la lista de posiciones y variantes pero considero que muchas de ellas, por su carácter creativo, merecen un análisis detenido que obviamente no podemos hacer aquí ${ }^{6}$ aunque, de entrada rechazamos el esquematismo y dogmatismo de la versión oficial soviética denominada dia-mat ${ }^{7}$. A pesar de las importantes aportaciones realizadas por todas estas corrientes a la filosofía en general y a la marxista en particular, considero que la concepción del marxismo como "filosofía de la praxis" que le otorgó Sánchez Vázquez en su libro clásico denominado de igual forma, descubre y desarrolla el aspecto fundamental y la transformación radical que propone Marx en su obra ${ }^{8}$, es decir, la consideración de que la "praxis" es el punto arquimédico de su pensamiento por varias razones:

5 El austromarxismo estuvo conformado por los que participaron en Marx Studien y la revista BlätterzurTheorieundPolitik des wissenschaftlichenSozialismusen 1914.

6 Otra causa de esta gran diversidad de posiciones tiene su origen en tres circunstancias: primera, en el desconocimiento que se tuvo de los manuscritos de Marx como fueron los Manuscritos económico-filosóficos de 1844 (década del treinta) y los Grundrisse (década de los sesenta del siglo pasado); segunda, la interpretación de la teoría de Marx a partir de otras tradiciones epistémicas (es clara la influencia del estructuralismo en Althusser y del historicismo en Gramsci, para solo poner dos ejemplos) pero la tercera es la más importante: Marx fue desarrollando una nueva concepción con un objetivo: hacer una teoría y crítica del sistema capitalista con el propósito de lograr un cambio hacia una sociedad justa y diferente.

7 Aquí habría que distinguir los diversos significados con que se ha usado el concepto "materialismo dialéctico" porque una cosa era la versión estalinista y posestalinista; otra la versión de Ludovico Geymonat y otra más la de Althusser. De igual forma, habría que hacerse cargo de que muchos filósofos que vivieron en los regímenes del llamado "socialismo realmente existente" tuvieron que colocar sus obras bajo dicho rubro sin que se ajustaran a la teoría oficial. Dos ejemplos fueron JindrichZeleny e Ilienkov.

${ }^{8}$ Karl Marx. Les Théses sur Feuerbach par Georges Labica, PUF, 1987.

\begin{tabular}{|l|c|c|c|c|}
\hline Q Romista Dialectus & Ano 5 & n.13 & Agosto-Dezembro 2018 & p. $116-131$ \\
\hline
\end{tabular}




\section{LA FILOSOFÍA DE LA PRAXIS. DOS CONCEPCIONES:...}

Gabriel Vargas Lozano

a) razón ontológica: el hombre es un ser ontocreador: crea una "segunda naturaleza" (la sociedad) con su praxis;

b) razón social: existe una dialéctica entre acción individual y estructura social;

c) razón gnoseológica: partir de la praxis implica la superación de los dos modelos clásicos: el empirista y el idealista que partían de la separación sujeto/objeto;

d) razón crítica: los productos de la praxis tienen un doble carácter: son expresiones objetuales de la esencia humana pero en las condiciones del capitalismo se encuentran sujetos a los procesos de enajenación, cosificación y fetichización; y finalmente,

e) la razón propiamente filosófica: una revolución profunda en dicho campo en dos direcciones: la consideración de que la filosofía es producto de la praxis expresada en las condiciones histórico-sociales en que surge y la necesidad de que la filosofía se interrelacione con la praxis para que sus ideales cobren realidad.

Pero aún entre los que pudieran coincidir en estas tesis existen múltiples diferencias como ocurre desde Labriola pasando por Korsch, Lukács, MihailoMarkovic, Gajo Petrovic, I. Mészáros, Karel Kosik, Antonio Gramsci y Sánchez Vázquez 9 .

Es por ello que el propósito de este trabajo es esclarecer las coincidencias y las diferencias de las dos importantes aportaciones que se han hecho en el marxismo: la concepción de Sánchez Vázquez y la de Antonio Gramsci. Considero que su contrastación puede tener como resultado una nueva y rica versión de la filosofía de la praxis que implicaría una aufhebung.

Características generales:

Es evidente que lo primero que hay que considerar es la diferencia de tiempo y circunstancias: Gramsci vivió entre 1891 y 1937 en Italia y bajo las condiciones más duras del fascismo. Admira su enorme capacidad de resistencia frente

9 Ver "Los sentidos de la filosofía de la praxis" en Gabriel Vargas Lozano (ed) En torno a la obra de Adolfo Sánchez Vázquez. Facultad de Filosofía y Letras. UNAM, México, 1995.

\begin{tabular}{|l|l|l|l|l|}
\hline Ronita Cialectus & Ano 5 & n.13 & Agosto-Dezembro 2018 & p. $116-131$ \\
\hline
\end{tabular}




\section{LA FILOSOFÍA DE LA PRAXIS. DOS CONCEPCIONES:...}

Gabriel Vargas Lozano

a los embates de Mussolini desde la cárcel; su extraordinaria cultura pero también sus sufrimientos personales.

Por su lado, la vida de Sánchez Vázquez transcurre entre 1915 y 2011, es decir, en un amplio período que le permitió ser partícipe y testigo de cambios históricos trascendentales: se integra a la lucha antifascista en la Guerra civil española y ante su derrota, es forzado al exilio; es testigo de la lucha contra el nazismo durante la Segunda Guerra Mundial; la posterior división del mundo en dos grandes bloques y finalmente, la caída del llamado "socialismo realmente existente" en Europa del este y la URSS (1989-1991) que produce una profunda crisis en la izquierda. Los dos comparten, por tanto, su anti-fascismo; su reflexión "no derrotista" de la derrota" Gramsci "pesimismo de la inteligencia y optimismo de la voluntad"); la advertencia, por parte de Gramsci del peligro de un cisma entre los dirigentes de la Revolución rusa a causa de la lucha por el poder cuyas consecuencias son extraídas por Sánchez Vázquez, en fecha posterior, con toda radicalidad. Los dos comparten un espíritu innovador que implica no quedarse en la exégesis de los textos clásicos sino en su repensamiento creativo frente a las novedades de la teoría y de la práctica; los dos recusan la versión cientificista del marxismo (el llamado "materialismo dialéctico" y en el caso de Sánchez Vázquez, la interpretación teoricista de Althusser) y finalmente los dos coinciden en considerar al pensamiento de Marx como una "filosofía de la praxis" que tiene rasgos originales.

Sánchez Vázquez cita a Gramsci en su libro Filosofía de la praxis en temas muy interesantes como el de la relación entre acción práctica y conciencia de la praxis; incorpora alguno de sus textos en la Antología de estética y marxismo y hace algunos ensayos sobre el revolucionario italiano, sin embargo, habrá que decir que no realiza sobre este autor un análisis tan acucioso como lo hace con Marx, Lenin o Althusser. Es por ello que considero que al libro clásico de Sánchez Vázquez, Filosofía de la praxis, le hace falta un capítulo de análisis y recuperación crítica.

Los dos autores parten de la convicción de que la filosofía de Marx se encuentra implícita en su obra y que hay que extraerla de ella, sin embargo, Gramsci toma como punto de partida de su reflexión, los libros publicados por los clásicos así como algunas cartas pero no alcanza a conocer los manuscritos. En cambio, Sánchez

10“Para leer a Gramsci en el Siglo XXI" en De Marx al marxismo en América Latina. Ed. Ithaca/BUAP, México, 1999, p. 99.

\begin{tabular}{|c|c|c|c|c|}
\hline Remista Dialectus & Ano 5 & n. 13 & Agosto - Dezembro 2018 & p. $116-131$ \\
\hline
\end{tabular}


Vázquez profundiza, entre otros, en los Manuscritos económico-filosóficos de 1844 que, como se sabe, provocan toda una revolución en el campo de la filosofía marxista.

Agregaría que es posible que los dos se hayan inspirado en Labriola. (18421904) que consideró también al materialismo histórico como una "filosofía de la praxis"

\section{Diferencias:}

Gramsci en los Cuadernos de la cárcel $^{2}$, profundiza en lo que llama la interrelación entre base económica; "sociedad civil" y "sociedad política". Propone la tesis de que el dominio de un bloque histórico presupone también la conquista de la hegemonía política, ideológica y filosófica y por ello se requiere analizar el papel de los intelectuales. Gramsci es creador de nuevos conceptos para conocer y buscar la transformación de una nueva realidad como lo fueron: intelectual tradicional; orgánico; transformismo; bloque histórico; hegemonía, nuevo príncipe; sociedad civil, sociedad política, guerra de posiciones; guerra de movimiento, ideología, americanismo, fordismo y muchos otros ${ }^{13}$.

En los Cuadernos de la cárcel $^{14}$ se propone realizar un vasto programa de investigación que comprende: el análisis de los intelectuales; la filosofía de Benedetto Croce, la obra de Maquiavelo, la crítica a Bujarin, americanismo, fordismo, el Renacimiento, la Reforma, el Risorgimento, Pasado y Presente, la traducción de los lenguajes científicos y filosóficos y otros, que tienen el objetivo de explicar, por un lado, la forma en que un bloque dominante (el burgués) logra la hegemonía y cuáles serían las características de la modernidad con el propósito de iniciar un tipo de sociedad radicalmente nueva. Aquí tenemos una extraordinaria aportación en el análisis de la conformación de la hegemonía y desde luego, la necesidad de conformar una alternativa.

En este sentido, Sánchez Vázquez en su conferencia dice: "el concepto de hegemonía y las diferentes estrategias con las que se vincula estrechamente (guerra de

\footnotetext{
${ }^{11}$ Autor de ensayos y obras importantes. Entre ellas, "En memoria del Manifiesto comunista" publicado en 1895 que se publicó en español en Biografía del Manifiesto comunista, Cia. General de ediciones, México, 1973; Del materialismo stórico, 1897, Discorrendo di socialismo e di filosofía, 1898

${ }^{12}$ Como se sabe, la reflexión de Gramsci a través de 32 cuadernos fue publicada por Palmiro Togliatti, de 1948 a 1951. Posteriormente se dará a conocer la edición crítica de Valentino Guerratana (1975) traducida al español y finalmente, se agregan nuevas aportaciones filológicas por Gianni Francionni a través de su obra en L'Officina gramsciana (1984) y Il problema filológico dei "Quaderni del carcere" di Gramsci (1998)

${ }^{13}$ Véase, Umberto Cerroni, Léxico gramsciano.Colegio Nacional de Socilogos, A.C. México, 1981.

${ }^{14}$ A. Gramsci, Cuadernos de la Cárcel en 6 tomos. Ed. Era, México, 1981. Traducción de la edición crítica de Valentino Guerratana, Einaudi, 1975.
}

\begin{tabular}{|c|c|c|c|c|}
\hline Qevista Dialectus & Ano 5 & n.13 & Agosto - Dezembro 2018 & p. $116-131$ \\
\hline
\end{tabular}


posiciones y guerra de movimientos) constituyen una de las contribuciones más fecundas y valederas de una estrategia política que responde a las circunstancias -el fracaso de las revoluciones de Occidente- que les dieron origen" ${ }^{15}$.

Gramsci, no conocerá los Manuscritos económico-filosóficos de 1844 ni textos como la Crítica a la filosofía del Estado de Hegel o los Grundrisse. El clima cultural en que vive está dominado por el historicismo en las vías desarrolladas por Benedetto Croce y Giovanni Gentile. Lo que ocurre es que Croce reduce al marxismo a un "canon de interpretación histórica" y le niega su carácter filosófico. Por su lado, Gramsci, a partir de sus análisis de dicho autor, caracteriza al marxismo como una filosofía de la praxis que tendría las siguientes características: se trata de un historicismo absoluto; un inmanentismo absoluto y un humanismo absoluto. Para Gramsci, la teoría de Marx es una nueva concepción original e independiente que se deslinda tanto del idealismo como del materialismo.

Por su lado, Sánchez Vázquez dice en un texto escrito para la Enciclopedia Iberoamericana de filosofia: "Por 'filosofía de la praxis' entendemos el marxismo que hace de la praxis su categoría central : como gozne en el que se articulan sus aspectos fundamentales, y eje en torno al cual giran su concepción del hombre, de la historia y de la sociedad, así como su método y teoría del conocimiento"16 y más adelante dice que los aspectos del marxismo son: crítica; proyecto de emancipación; conocimiento y vinculación con la práctica ${ }^{17}$

En su libro Filosofía de la praxis, en primer término, hace una lectura semántica del concepto de praxis desde la filosofía clásica hasta Hegel; profundiza en la revolución teórico-práctica operada por Marx y pone énfasis en que hay una profunda diferencia entre la noción de praxis y poiesisen Aristóteles y su significado en Marx. En esta dirección, precisa la forma en que entenderá los conceptos de "práctica", "praxis", “filosofía de la praxis"; profundiza sobre las relaciones entre teoría y praxis; desarrolla temáticas como la ética, la estética, la ideología, utopía, la filosofía política y la concepción del socialismo.

\section{Concepciones de la filosofía.}

\section{La filosofía para Gramsci.}

\footnotetext{
15،"Para leer a Gramsci...op.cit., p. 104

${ }^{16}$ Adolfo Sánchez Vázquez "La filosofía de la praxis" en Filosofía política I. Ideas políticas y movimientos sociales. Edición de Fernando Quesada. Enciclopedia Iberoamericana de filosofía. Ed. Trotta, Madrid, 1997, p. 17.

${ }^{17}$ Loc. Cit., p. 20.
}

\begin{tabular}{|l|l|l|l|l|}
\hline Ronita Dialectus & Ano 5 & n.13 & Agosto - Dezembro 2018 & p. $116-131$ \\
\hline
\end{tabular}


En forma muy sintética diríamos que Gramsci considera que la filosofía es un "orden intelectual"18, sin embargo, este orden está vinculado estrechamente con la sociedad, la historia, la cultura y la política. Es por ello que examina los diversos grados de expresión de este "orden" desde las concepciones del mundo sostenidas por una persona en forma más o menos inconsciente hasta sus expresiones más abstractas. En el Cuaderno undécimo de la cárcel titulado "Apuntes para una introducción y preparación al estudio de la filosofía y de la historia de la cultura" dice: "conviene, por tanto, demostrar de entrada que todos los hombres son "filósofos", definiendo los límites y los caracteres de esa "filosofía espontánea", propia de "todo mundo", a saber, de la filosofía contenida: 1) en el lenguaje mismo, que es un conjunto de nociones y de conceptos determinados, y no sólo de palabras gramaticalmente vacías de contenido; 2) en el sentido común y en el buen sentido; 3) en la religión popular y también, por consiguiente, en todo el sistema de creencias, supersticiones, opiniones, maneras de ver y de actuar que asoman en eso que generalmente se llama 'folklore"'. 19

Hay que criticar y hacer consciente esa concepción del mundo. Criticar la propia concepción del mundo significa, pues, hacerla unitaria y coherente y elevarla hasta el punto alcanzado por el pensamiento mundial más avanzado". ${ }^{20}$

La filosofía es crítica y superación de la religión y el sentido común.

La tesis de Gramsci es que una filosofía se convierte en movimiento cultural, religión, fe, ideología. La ideología es una concepción del mundo que "se manifiesta implícitamenteen el arte, en el derecho, en la actividad económica, en todas las manifestaciones de la vida, individuales y colectivas". ${ }^{21}$

"La relación entre filosofía "superior" y sentido común queda asegurada por la política". 22

\section{La filosofía para Sánchez Vázquez}

La forma de entender la filosofía para Sánchez Vázquez es un tanto diferente aunque no opuesta. Para él, "El marxismo representa una innovación radical

\footnotetext{
18“La filosofía es unorden intelectual, cosa que no pueden ser ni la religiónniel sentido común” Antonio Gramsci, Introducción al estudio de la filosofía. Prólogo de Manuel Sacristán. Ed. Crítica, Barcelona, 1985, pp 42-43.

${ }^{19}$ Op. Cit., p. 39. Aquí hago notar que Gramsci pone el concepto "filosófos" entre comillas ya que tiene muy clara la diferencia entre una "filosofía espontánea" o concepción del mundo y una sistematizada".

${ }^{20}$ Op. Cit. pp 40-41.

${ }^{21}$ Op. Cit. p. 46.

${ }^{22}$ Op. Cit. p. 49.
}

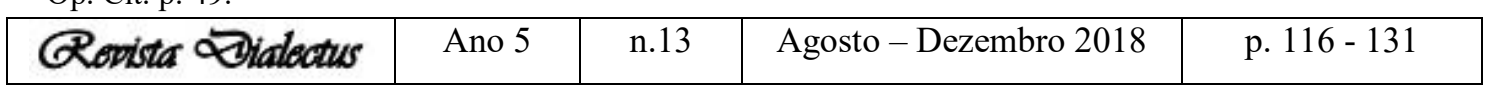




\section{LA FILOSOFÍA DE LA PRAXIS. DOS CONCEPCIONES:...}

Gabriel Vargas Lozano

en la filosofía. Su novedad estriba en ser una nueva práctica de la filosofía, pero lo es justamente por ser una filosofía de la práctica". ${ }^{23}$

Pero ¿qué es la praxis? En su Filosofía de la praxis, la define como "la actividad práctica material, adecuada a fines, que transforma el mundo natural y humano" 24 Para Sánchez Vázquez la praxis es una actividad pero no toda actividad es praxis. La actividad propiamente humana implica un carácter consciente; es decir, la formación de conceptos, hipótesis, teorías, conocimientos y fines pero ello no la convierte en praxis. Aquí encontramos una diferencia esencial con respecto a la posición de Louis Althusser quien habla de la "práctica teórica".

Ahora bien, Sánchez Vázquez distingue "praxis" de "práctica". Para él, práctica es "actividad o ejercicio" y "teoría" es "visión, contemplación o descubrimiento". A pesar de sus complejas interrelaciones, la teoría "por sí misma no es acción real, transformación efectiva o praxis"25

Para Sánchez Vázquez, la diferencia de Marx con respecto de los anteriores es que toma como categoría central a la praxis pero no sólo como reflexión sino también como transformación. Se distingue así de las filosofías interpretativas que si bien pueden o no interesarse en la transformación de la realidad están vinculadas a la práctica, de alguna manera ${ }^{26}$. La novedad de Marx, para ASV, se encuentra en el "modo de hacer filosofía". El punto clave es que la filosofía se tiene que ver como un momento de la praxis. La especificidad es que la teoría misma debe insertarse en la transformación del mundo. La filosofía de la praxis supone una opción ideológica, un punto de vista de clase. Sus funciones son: a) crítica (crítica de las ideologías conciliadoras y crítica política); b) gnoseológica; c) conciencia de la praxis o "la praxis que toma conciencia de sí misma” y d) autocrítica. Se trata de la función práctica de la teoría. En otras palabras, la filosofía, antes de Marx (y por cierto, también después de él) se ha dedicado a reflexionar sobre el mundo proponiendo, en algunos casos, soluciones a problemas. Ahora se trata de que explícitamente se convierta en conciencia de la praxis. ASV dice que "La racionalidad de una determinada praxis histórica no radica en el conocimiento del objeto sino también en su ajuste a ese fin último a través

\footnotetext{
23“"La filosofía de la praxis como nueva práctica de la filosofía" incluida en Ensayos marxistas sobre filosofia e ideología. Ed. Oceano, Barcelona, 1983, p. 35. Ponencia presentada en el IX Congreso Interamericano de filosofía, Caracas, junio de 1977.

${ }^{24}$ Adolfo Sánchez Vázquez, Filosofia de la praxis. Siglo XXI editores, México, 2003, p. 281.

${ }^{25}$ Ensayo, p. 37.

${ }^{26}$ En su ensayo "la filosofía, sin más ni menos" analiza la compleja relación entre la teoría y sus relaciones con la práctica".
}

\begin{tabular}{|c|c|c|c|c|}
\hline Qonista Dialectus & Ano 5 & n.13 & Agosto - Dezembro 2018 & p. $116-131$ \\
\hline
\end{tabular}




\section{LA FILOSOFÍA DE LA PRAXIS. DOS CONCEPCIONES:...}

Gabriel Vargas Lozano

de su inserción de la praxis que lo realiza" ${ }^{27}$ La filosofía de la praxis no se reduce a un cambio de objeto sino implica una nueva práctica de la filosofía: su relación necesaria y racional con la praxis.

\section{El problema del materialismo}

Los dos autores coinciden, a partir de su interpretación de las Tesis sobre Fuerbach que el conocimiento no debe ser concebido mediante una confrontación especulativa entre objeto y sujeto y que el centro es la praxis, sin embargo, existe un punto clave de diferenciación ya que Gramsci extiende la crítica de Marx al materialismo contemplativo de Feuerbach a toda formulación que se realice bajo la concepción de "materialismo" y en especial se dirige en contra del "materialismo dialéctico" de Plejanov y Bujarin. En lo que se refiere a Marx, se sabe que justamente la critica que le dirige a Feuerbach es la ausencia de la categoría de praxis, sin embargo, un año antes, en los Manuscritos económico-filosóficos de 1844, había escrito que, por un lado, Feuerbach tenía el mérito de ser el primero que había criticado a la filosofía de Hegel como una "teología racionalizada" pero, a su vez, su defecto había sido el de no haber captado lo esencial del autor de la Fenomenología del espíritu que era su "método dialéctico". Marx considera, entonces, que su método es tanto "materialista" como "dialéctico". Lo que ocurre posteriormente con Plejanov, Bujarin y más tarde, con Stalin es la adjudicación de un nuevo significado a la díada "materialismo dialéctico" o "dia-mat" que transforma a la filosofía de la praxis de Marx en "filosofía como ciencia de las ciencias" que no es una tesis sostenida por el autor de El capital. Gramsci, rechaza la interpretación cientificista que considera una deformación debido a que convierte a la teoría de Marx en una mecanicismo pero agrega que Bujarin, a quien dirige sus críticas, recae en una concepción religiosa debido a que la diferencia entre materia y espíritu es de origen religioso y por tanto, debe ser rechazada ${ }^{28}$. Es por ello que Gramsci, en lugar de "materialismo" habla de "inmanentismo" y además de "inmanentismo absoluto". En este punto, considero que Gramsci tuerce el bastón para el otro lado, en su lucha en contra del positivismo. No podemos hacer aquí una historia del concepto "inmanentismo" que se iniciaría con Aristóteles, se desarrollaría con los medievales, Spinoza, Fichte, Kant hasta llegar a Gentile y que implicaría en este último,

\footnotetext{
${ }^{27}$ Ensayos marxistas...p. 45.

${ }^{28}$ Gramsci dice "El modo como se plantea (Bujarin) el problema de la "realidad objetiva del mundo externo" es superficial y extraño al materialismo histórico. El autor no conoce la tradición católica y no sabe que precisamente la religión sostiene encarnizadamente esta tesis contra el idealismo, de modo que la religión católica sería en este caso "materialista". Cuaderno 7, en Cuadernos de la cárcel. T. 3, p. 180.
}

\begin{tabular}{|l|l|l|l|l|}
\hline Rovista Dialectus & Ano 5 & n.13 & Agosto-Dezembro 2018 & p. $116-131$ \\
\hline
\end{tabular}


una prioridad de la conciencia sobre la materia ${ }^{29}$. Ahora bien, Gramsci no sostiene la posición hegeliana de Gentile pero no quiere llamar materialismo al inmanentismo. Aquí encuentro un problema sujeto a debate.

Por su lado, Sánchez Vázquez también recusa las teorías del conocimiento del idealismo y del materialismo contemplativo pero afirma el materialismo, la dialéctica y la praxis como mediación central. El materialismo no sólo significaría el reconocimiento de una realidad objetiva sino el proceso de transformación que los hombres realizan de la naturaleza con su praxis creando a la sociedad. Sánchez Vázquez sostiene la tesis de un materialismo práctico.

\section{La relación ciencia-ideología.}

Otra diferencia entre los dos autores es en torno a la relación entre ciencia e ideología.

Ya hemos mencionado que Gramsci se opone a la versión cientificista del marxismo sostenida por Bujarin pero Gramsci va más allá al considerar que la ciencia es parte de la superestructura. Lo que podríamos decir al respecto es que hay muchos aspectos relacionados con la investigación o la aplicación de la ciencia que están vinculados a la superestructura, sin embargo, diversos aspectos de la ciencia natural perduran más allá de los cambios estructurales y superestructurales. En esta dirección polémica, Gramsci no aprecia la aportación que hizo la delegación soviética, presidida por Bujarin, a la historia y la sociología de la ciencia en el importante congreso celebrado en Londres en $1931^{30}$

ASV analiza, en forma acuciosa, el tema de la relación entre ciencias sociales e ideología en diversos textos pero en especial en "La ideología de la "neutralidad ideológica" en las ciencias sociales" presentada inicialmente en el Primer Coloquio Nacional de Filosofía celebrado en Morelia, en el año de 1975. Su concepción es que, a diferencia de las ciencias naturales, en el caso de las ciencias sociales existe una relación específica con las ideologías ${ }^{31}$.

En otras palabras, considero que Gramsci concibe a la ciencia sólo en su versión positivista. Por tanto, de acuerdo con su historicismo, considera que no es

${ }^{29}$ Un diálogo interesante sobre el materialismo, lo encontramos en El materialismo de Werner Post y Alfred Schmidt, Ed. Herder, Barcelona, 1976.

30“"II Congreso Internacional de Historia de la Ciencia y la Tecnología" Londres, del 29 de junio al 3 de julio de 1931 y cuyas ponencias se publicaron en el libro Science at the Cross Roads.

${ }^{31}$ En efecto, en dicho ensayo dice, por un lado, que no hay barrera insalvable entre las ciencias naturales y sociales: que las ciencias sociales son objetivas pero que su objetividad es valorativa, es decir, en "ellas no se escinden objetividad y valor" "La ideología de la "neutralidad ideológica" en las ciencias sociales" en Ensayos marxistas sobre filosofia e ideología. Ed.1983, Oceano, Barcelona,p. 149

\begin{tabular}{|l|c|c|c|c|}
\hline Q & Anista \\
\hline
\end{tabular}


aplicable al análisis social. Por su lado, Sánchez Vázquez distingue entre ciencias naturales y ciencias sociales; considera que existe, por un lado, una continuidad en lo que se refiere a la búsqueda de objetividad pero también una discontinuidad por la diferencia de los objetos analizados y por último, rechaza, por un lado, la concepción neokantiana de las dos ciencias así como las tesis positivistas o neo-positivista de ellas.

En torno a la ideología, mientras Gramsci habla de la ideología como concepción del mundo que extrae del Prólogo a la Contribución a la crítica de la economía política de 1859, Sánchez Vázquez habla de los dos sentidos del concepto en Marx: uno, extraído de la Ideología Alemana como "conciencia invertida de la realidad" y otro más amplio ${ }^{32}$

Pero además, derivado del concepto de ideología, Sánchez Vázquez propone un análisis muy interesante del concepto de utopía en su libro Del socialismo científico al socialismo utópico en donde si bien acepta la tesis de Engels de que no puede emprenderse una transformación práctica de la realidad sin realizar un análisis científico de ella, como pretendían Owen, Fourier o Saint Simón, también reivindica el concepto de utopía como un horizonte necesario de la praxis social.

El tema de la ideología ha alcanzado una complejidad mayor a partir de las interpretaciones de Wolfgang Fritz Haug, Pierre Bordieu, Göran Therborn, Louis Althusser, Theodor Adorno, Jacques Lacan, Fredric Jameson, etc. ${ }^{33} \mathrm{Y}$ en el caso de la utopía tenemos la esclarecedora reflexión de Ernst Bloch en su importante libro titulado Principio Esperanza.

\section{Partido y conciencia de clase}

Un último aspecto al que quiero referirme brevemente es el de la relación entre el partido y la conciencia de clase.

En la conferencia que ASV impartió sobre la vigencia de Gramsci para el siglo XXI, le dirige una crítica al pensador italiano en torno a la influencia que ejercen en su reflexión las concepciones de Lenin sobre la concepción del partido; la tesis de las dos conciencias (sindicalista y socialista) y la importación por el Partido de la conciencia de clase desde el exterior. Para Sánchez Vázquez, la tesis de Lenin en el ¿Qué hacer? posibilita que un grupo de dirigentes se considere el poseedor de la verdad

\footnotetext{
32،"La ideología es: a) un conjunto de ideas acerca del mundo y la sociedad que: b) responde a intereses, aspiraciones o ideales de una clase social en un contexto social dado y que: c) guía y justifica un comportamiento práctico de los hombres acorde con esos intereses, aspiraciones o ideales”. Op. Cit. p. 145.

${ }^{33}$ Vid. SlavojZiZek (comp.) Ideología, un mapa de la cuestión. FCE, Buenos Aires, 2003.
}

\begin{tabular}{|l|c|c|c|c|}
\hline Q & Anista \\
\hline
\end{tabular}


y por tanto, estaría facultado para dirigir a toda la sociedad "en nombre de la ciencia". Esta concepción del partido es, desde su punto de vista, uno de los aspectos que impidieron el desarrollo de una auténtica democracia en lo que se llamó el "socialismo realmente existente" y que se contrapondría a un auténtico socialismo democrático. En opinión de Sánchez Vázquez, Gramsci está influido hasta cierto punto por estas concepciones, sin embargo, reconoce que el autor de los Cuadernos de la cárcel no se limita a ellas y considera que la dirección intelectual y moral que debe sostener el nuevo príncipe requiere necesariamente del consenso de las clases subalternas pero también de otra concepción de la ideología. A mi juicio, esta es una aportación fundamental de Gramsci sobre la cual Sánchez Vázquez no profundizó.

\section{Conclusión}

La comparación de estas dos interpretaciones de la filosofía de la praxis nos permite aclarar en qué sentido cada autor reflexiona sobre aspectos distintos pero no necesariamente opuestos:

Por un lado, tenemos que Gramsci desarrolla su importante teoría de los intelectuales, el bloque histórico, la hegemonía, guerra de posiciones, guerra de movimiento, catarsis y otras categorías para explicar cómo domina la clase dominante; para analizar la traductibilidad de los lenguajes científicos y filosóficos y precisar las características de la modernidad capitalista en Europa.

Por su lado, Sánchez Vázquez no utiliza esta terminología y no avanza por esa vía sino en otros aspectos como: precisión conceptual de praxis; diferenciación entre praxis creadora y reiterativa; el tema de la racionalidad, la violencia; las relaciones entre ética y política y los problemas del socialismo que sólo aparecen en forma incipiente en tiempos de Gramsci.

Pero la lectura de Gramsci a partir de la obra de Sánchez Vázquez nos permite fundamentar mejor, como hemos visto, los conceptos de "praxis"; "filosofía"; "materialismo"; "ciencia social" "ideología", "socialismo" y "democracia". A su vez, la lectura de Sánchez Vázquez a partir del enfoque gramsciano nos permite profundizar en las concepciones del mundo que integran la hegemonía de un bloque histórico dado.

Como he dicho al principio, hoy se requiere vincular estas dos sendas de la filosofía de la praxis para que los grupos y fuerzas sociales cumplan mejor su fin principal que sería el de la transformación de la sociedad.

\section{BIBLIOGRAFÍA:}

\begin{tabular}{|l|l|l|l|l|}
\hline Gonita Dialectus & Ano 5 & n.13 & Agosto-Dezembro 2018 & p. $116-131$ \\
\hline
\end{tabular}


Obras de Adolfo Sánchez Vázquez utilizadas o mencionadas:

Las ideas estéticas de Marx. Ediciones Era, México, 1965, 293 págs. (Reediciones en la Habana. Cuba, 1966 y 1973.- Reedición en prensa del Editorial Siglo XXI, México, D.F., con prólogo de Federico Álvarez).

Filosofía de la praxis. Editorial Grijalbo, México, 1967, 387 págs. Nueva edición revisada y ampliada, 2005, Ed. Grijalbo, México, 1980 y Ed. Critica, Barcelona, España, 1980, 429 págs. Reedición en prensa de Siglo XXI, México, con prólogo de Francisco José Martínez.

Ética.Editorial Grijalbo, 1969, 240 págs. (65 ediciones hasta en 2005). Reedición de Ed. Crítica, Barcelona.

Estética y marxismo (antología), 2 vols., Ediciones Era, México, 1970 (Vol. 1, 431 págs.; vol. 2, 525 págs.

Del socialismo científico al socialismo utópico. Ediciones Era, Col. Popular, México, 1975, 78 págs.

Ciencia y revolución (El marxismo de Althusser). Alianza Editorial, Madrid, 1978, 210 págs. (con un intercambio de cartas entre EtienneBalibar y el autor).

Filosofía y economía en el joven Marx(Los Manuscritos de 1844).Editorial Grijalbo, México, 1982, 287págs. (Reedición en prensa con el título de Eljoven Marx de Ed. Ítaca y UNAM), México, D.F., 2004.

Ensayos marxistas sobre filosofía e ideología. Ediciones Océano, Barcelona, España, 1983, 207págs.

Ensayos marxistas sobre historia y política. Ediciones Océano, México, 1985, 207 págs.

Escritos de política y filosofía. Fundación de Investigaciones Marxistas y Editorial Ayuso, Madrid, 1987, 263 págs.

Invitación a la Estética. Editorial Grijalbo, México, D.F., 1992, 273 págs. (Nueva edición, 2006).

Filosofía y circunstancias. UNAM, México, D.F., y Editorial Anthropos, Barcelona, 1997, 426 págs.

El mundo de la violencia, (como Editor), Universidad Nacional Autónoma de México/Fondo de Cultura Económica, México, 1998, 457 págs.

Entre la realidad y la utopía. Ensayos sobre política, moral y socialismo. UNAM/Fondo de Cultura Económica. 1999, 329 págs.

De Marx al marxismo en América Latina. Ed. Ítaca en coedición con la Facultad de Filosofía y Letras de la Universidad Autónoma de Puebla, 1999, 263 págs.

\begin{tabular}{|c|c|c|c|c|}
\hline Qovista Dialectus & Ano 5 & n.13 & Agosto - Dezembro 2018 & p. $116-131$ \\
\hline
\end{tabular}


El valor del socialismo. Editorial Ítaca, México, D. F., 2000, 162 págs. Reedición de El Viejo Topo, Barcelona, 2003.

A tiempo y destiempo (Antología de ensayos). Fondo de Cultura Económica, México, D. F., 2005.

Una trayectoria intelectual comprometida. UNAM, 2006; otra ed., Creación, estética y filosofía política. Mi recorrido intelectual, Presentación de Ambrosio Velasco Gómez, Madrid, Univ. Complutense, 2007 (Estudios Filosóficos).

Ética y política. FCE/UNAM, 2007 (Filosofía).

Obras de o sobre Antonio Gramsci:

Antonio Gramsci, Cuadernos de la cárcel. Seis volúmenes. Ed. Era, México, 19852000 .

Kanoussi Dora, Los cuadernos filosóficos de Antonio Gramsci. De Bujarin a Maquiavelo. Cuidado de la edición: Cristina Ortega Kanoussi. UACM, BUAP, Plaza y Valdés, México, 2007.

Löwy, A.G. El comunismo de Bujarin. Grijalbo, 1972.

Baron Samuel H. Plejanov, el padre del marxismo ruso. Siglo XXI, 1976.

Tom Bottomore, A dictionary of Marxist thought. Secondedition. Blackwell, 1991.

Kanoussi Dora, Una Introducción a Los Cuadernos de la cárcel de Antonio Gramsci, Prólogo de GiusseppeVacca, BUAP, International Gramsci Society. Plaza y Valdez, México, 2000.

Gramsci. A. Edición Nacional 125 volúmenes. Escritos 1910-26. Introducción de Leonardo Paggi. Cuadernos de la Cárcel. Introducción de Gianni FrancioniEpistolario: 1906-1937.

Löwy, M, El marxismo olvidado. Fontamara, 1978.

Haug, W.F. "Filosofando con Gramsci y Brecht”.Bujarin, Nikolai, I. Ensayo popular de sociología. Siglo XXI, 1978. Cuadernos de P y P.

Bujarin, "Teoria e prassidal punto di vista del materialismo storico" en Scienza al bivio, interventideidelegatisovietici al Congressointernacionali di storiadellascienza e della tecnología. De Donato, 1977. Science at the Cross Roads. London-1931.

Coutinho Nelson. Gramsci. 1999.

Vacca, G. EI marxismo de los intelectuales. UAS, Culiacán, 1984.

Liguori, Guido.Gramsci conteso, storia di un debatito. 1922-1996.

\begin{tabular}{|c|c|c|c|c|}
\hline Qovista Dialectus & Ano 5 & n.13 & Agosto - Dezembro 2018 & p. $116-131$ \\
\hline
\end{tabular}


www.internationalgramscisociety.org

Revista Dialéctica. Número especial dedicado a Gramsci. N. 26. Verano/otoño de 1994.

Francioni, Gianni, L'oficina gramsciana/Ipotesisullastruttura del Quaderni del carcere. Bibliopolis, Napoles.1984.

Cerroni, Umberto, Léxico gramsciano. Colegio Nacional de sociólogos, México, 1981 Díaz-Salazar, Rafael, El proyecto de Gramsci. Ed- Anthropos, Barcelona, 1991.

Texier, Jacques, Gramsci. Ed. Grijalbo, Barcelona, 1976.

Fiori, Giuseppe.Vida de Antonio Gramsci, Barcelona, 1968.

Kanoussi Dora (compiladora).Gramsci en América. II Conferencia Internacional de estudios gramscianos. BUAP, Antonio Gramsci, A.C., Plaza y Valdes editores, México, 2000 .

Belaval, Yvon. Dirección. Las filosofías nacionales. Siglos XIX y XX. Siglo XXI editores, México, 1981.

Recursos electrónicos:www.fondazionegramsci.org/

\begin{tabular}{|l|l|l|l|l|}
\hline Qevista Qialectus & Ano 5 & n.13 & Agosto - Dezembro 2018 & p. $116-131$ \\
\hline
\end{tabular}

